\title{
Why borderline personality features adversely affect job performance: The role of task strategies
}

\author{
Rebecca J. Thompson*, Stephanie C. Payne, Margaret T. Horner, Leslie C. Morey \\ Texas A\&M University, 230 Psychology Building, 4235 TAMU, College Station, TX 77840-4235, United States
}

\section{A R T I C L E I N F O}

\section{Article history:}

Received 20 May 2011

Received in revised form 19 August 2011

Accepted 24 August 2011

Available online 1 October 2011

\section{Keywords:}

Borderline Personality Disorder

Job performance

Strategy

Task performance

\begin{abstract}
A B S T R A C T
This study examined how Borderline Personality Disorder (BPD) and its components influence job performance. BPD is theorized to adversely affect the generation of task strategies in the workplace which results in poor job performance. In this study, 180 college students completed the Borderline Scale from the Personality Assessment Inventory (PAI-BOR; Morey, 1991) followed by a work-related simulation. While none of the facets of BPD related to task strategy, the composite of borderline negatively related to task strategy, which was positively related to task performance. Thus, borderline appears to have an indirect effect on task performance through task strategy.
\end{abstract}

(c) 2011 Elsevier Ltd. All rights reserved.

\section{Introduction}

The health of employees and how it affects organizational outcomes has become a topic of increasing interest to organizational researchers (Jex \& Crossley, 2004). However, a study of the impact of individuals' mental health on organizational outcomes such as job performance is merited in order to better understand its impact on the organization. The Diagnostic and Statistical Manual of Mental Disorders-IV (DSM-IV: American Psychiatric Association, 1994) has noted that personality disorders may be particularly problematic in organizations, because these disorders reflect personality traits that are enduring and long-lasting patterns of maladaptive behavior, rather than a more transient or episodic emotional problem. Borderline Personality Disorder (BPD) is the most frequently diagnosed personality disorder in clinical settings (Trull, Useda, Conforti, \& Doan, 1997), and individuals diagnosed with this disorder demonstrate multiple behaviors that are potentially disruptive in employment settings.

The purpose of this study is to examine how borderline personality and its features influence task strategies employed, as well as the resulting task performance in a workplace simulation. The following paragraphs describe job performance and task strategies, the various features of borderline personality, and how and why borderline personality and its corresponding features are expected to negatively relate to job performance.

\footnotetext{
* Corresponding author. Tel.: +1 9039181531.

E-mail address: BeckersD13@aol.com (R.J. Thompson).
}

\subsection{Job performance}

Job performance has been defined as "behavior or action that is relevant for the organization's goals and that can be scaled (measured) in terms of the level of proficiency (or contribution to goals) that is represented by a particular action or set of actions" (Campbell, 1999; p. 402). According to Campbell and his colleagues (Campbell, 1990; Campbell, McCloy, Oppler, \& Sager, 1993), job performance is a multidimensional construct consisting of eight dimensions, one of which is job-specific task proficiency. Job-specific tasks are the tasks that are most central to the job, or the tasks that distinguish one job from another. In this study, we focus on job-specific task proficiency or "task performance," because these proficiencies are the most fundamental units of successful job performance. Thus, individuals must be successful at task performance in order to be successful at their jobs and therefore in an organization.

\subsection{Task performance}

Task performance "involves activities that directly transform raw materials into the goods and services that are the organization's products" or "activities that service and maintain the technical core" (Motowidlo, 2003, pp. 43-44). Task performance varies by job but represents the core behaviors required for a given job. For example, task performance entails checking out customers by a grocery store cashier, repairing a flat tyre by an auto mechanic, and changing diapers by a daycare worker.

In order to achieve maximum performance, individuals must plan their course of action or strategize the most efficient and 
effective ways to perform the task (Campbell, 1991). The amount of autonomy employees have varies from job to job; some jobs may have strict policies concerning the strategies employees should use, while others permit some discretion and strategizing. These strategies may reflect behaviors proximal to job performance in the workplace.

\subsection{Task strategies}

Task (performance) strategies are "the methods and procedures an individual uses in attempting to achieve a task's objectives" (Campbell, 1991, p. 3). The more complex the task, the more task strategies there are likely to be (Campbell, 1988, 1991; Terborg \& Miller, 1978). Campbell (1991) explained that the amount and quality of strategies an individual develops are dependent on the amount of cognitive effort an individual spends while reflecting on the task. First, an individual will identify strategies that require the least amount of cognitive effort (Campbell, 1991). These are generally strategies that have been used in the past and are considered relevant based on characteristics of the task at hand. With deeper reflective thought, individuals are likely to produce additional strategies that may prove more useful for completing the task (Campbell, 1991). According to social-cognitive theory, task strategies provide a means for regulating one's task-specific selfefficacy or motivation for completing the task (Bandura, 1986). Correspondingly and consistent with previous empirical studies (Audia, Kristof-Brown, Brown, \& Locke, 1996), we anticipate that the more strategies one attempts, the better his/her performance.

\section{H1. Task strategy use is positively related to task performance.}

\subsection{Borderline Personality Disorder}

Borderline Personality Disorder is defined by the DSM-IV as "a pervasive pattern of instability of interpersonal relationships, self-image, and affects, and marked impulsivity beginning by early adulthood and present in a variety of contexts" (American Psychiatric Association, 1994). The estimated prevalence of BPD is about $2 \%$ of the general adult population (American Psychiatric Association, 1994), or roughly 4.3 million of the 216 million adults in the United States (US Census Bureau, 2008). Individuals with BPD often have highly volatile relationships characterized by periods of adoration and idealization followed by suspicion and coldness, which stems from a fear of abandonment. They are also described as being extremely impulsive as well as having very unstable emotional states. These features in combination with an unsteady sense of identity often lead them to make irrational choices that are self-damaging (American Psychiatric Association, 1994). However, even individuals with clinical levels of BPD may be functional and therefore employed in an organization.

Individuals with BPD often have difficulty with occupational functioning. When compared to individuals with other personality disorders, individuals with BPD are less likely to have education beyond high school and despite the potential to contribute to organizational performance, they are less likely to sustain employment (Zanarini, Frankenburg, Hennen, Reich, \& Silk, 2005), more likely to receive disability payments (due to psychiatric problems), seek medical attention at higher rates, and are less likely to perform well at work (Zanarini et al., 2005). Other common work-related problems include a lack of satisfaction with work, unrealistically high expectations of perfection for themselves, avoidance/procrastination, and overall poor work habits (Salz, 1983). These issues may be salient in selecting individuals, making task assignments and delegating responsibilities, and when forming highly interdependent teams. This is not to say that individuals with BPD cannot be effective workers or have successful careers. In some cases, these individuals "may use their work as a vehicle to involve themselves with others, because ordinary intimacy remains difficult" (Leader, 1994, p. 8). However, although individuals with BPD frequently recover from the problems related to their psychological functioning in social contexts, they are still not as likely to have successful careers as individuals diagnosed with other Axis II disorders (Zanarini et al., 2005).

While BPD reflects a psychiatric diagnosis, it is important to keep in mind that personality disorders are exaggerations of personality styles and characteristics that exist within all individuals (Oldham, 1995). "It is the quantity of each personality style along a continuum, not its quality, that tends to spell problems in life" (Oldham, 1995, p. 21). Thus as any individual's score increases on a feature of BPD, so does the likelihood that he/she may be at risk for problems associated with that feature.

\subsection{Facet characteristics of borderline personality}

It is generally recognized that the concept of borderline personality represents an amalgam of a number of lower-order component personality characteristics (e.g., Grinker, Werble, \& Drye, 1968; Sanislow et al., 2002). These components are represented on some commonly used measures of BPD, such as the Diagnostic Interview for Borderlines (DIB: Gunderson, Kolb, \& Austin, 1981) or the Borderline Scale from the Personality Assessment Inventory (PAI-BOR; Morey, 1991). For example, the BOR scale consists of four subscales: Self-harm, Identity Problems, Affective Instability, and Negative Relationships (Morey, 1996). Each subscale is measured on a continuum permitting an examination of how increases in these characteristics relate to theoretically relevant behaviors. The assessment of the lower-level features that comprise this disorder permits an examination of how specific aspects of borderline personality might affect task strategy and performance.

The first subscale, Self-harm, involves a pattern of impulsivity where little if any consideration is given to the repercussions that result from these actions. The term "Self-harm" reflects the fact that the erratic actions often lead to deleterious effects on the individual, which may include poor work performance. Several studies have shown that individuals with BPD do not perform well on tasks that require response inhibition (Bazanis et al., 2002; Hochhausen, Lorenz, \& Newman, 2002; Rentrop et al., 2008). For example, Rentrop et al. (2008) argued that the inability to inhibit a predominant response to stimuli combined with a short reaction time indicates that individuals with BPD are likely to have difficulty planning their behavior which is a substantial part of strategizing.

Additionally, Bazanis et al. (2002) found that patients with BPD not only have trouble making plans but also have trouble making decisions and controlling impulses (Bazanis et al., 2002). We speculate that individuals with a high level of impulsivity as reflected by a high score on the self-harm scale will generate fewer task strategies which in turn will result in lower levels of task performance.

H2. Self-harm is negatively related to (a) task strategy and (b) task performance.

The Identity Problems scale indicates problems related to an unstable self-identity whereby high scorers rely on others to help them determine their goals and ambitions (Morey, 1996). These individuals become attached to others they feel close to in order to establish a sense of identity that they are not capable of defining for themselves. Goals stimulate task strategy development (Campbell, 1991; Locke, Shaw, Saari, \& Latham, 1981), and thus ambiguity around goals and ambitions would be expected to impede such development. Individuals who score high on the identity problems 
scale may find it difficult to determine how they should perform the task, because they lack specific self-set goals. Therefore, we hypothesize that identity problems will adversely affect task strategy generation and performance.

H3. Identity problems are negatively related to (a) task strategy and (b) task performance.

High scores on the Affective Instability scale reflect emotional reactivity and variability characterized by sudden, intense mood swings. Performing cognitively demanding tasks that require planning and decision-making may be challenging for individuals with high levels of affective instability because reactivity to any emotional dimensions of the task, whether actual or perceived, may affect their ability to focus on the task. For example, Forgas and George (2001) note that "[t]asks that require elaborate, substantive processing are most likely to be influenced by affect, as mood will selectively prime affect-related thoughts and memories to be used when constructing a response" (p. 4). Therefore we hypothesize:

H4. Affective instability is negatively related to (a) task strategy and (b) task performance.

The final subscale, Negative Relationships, reflects "a tendency to repeatedly become involved in relationships that are very intense and chaotic" (Morey, 1996, p. 59). This feature is likely to affect borderline individuals' relationships at work, especially if the nature of their work requires repeated interaction or interdependence with coworkers. In this study, the participants only interact with the experimenter; therefore we do not expect this feature to be particularly salient to performance for participants in this study.

While these features in isolation may characterize other personality disorders, the combination of these features represents a particularly challenging pattern of personality features (Morey, 1996). Thus, high scores on any of the individual subscales have the potential to indicate problems in functioning, as they are also indicative of other personality disorders. However, it is the interrelationship of these features that leads to the problems individuals with BPD experience, which is unique from individuals with other disorders. Because of this distinctive combination of traits, we hypothesize that borderline personality (i.e., at the full scale level of PAI-BOR) will be negatively related to task strategy and task performance.

H5. Borderline personality is negatively related to (a) task strategy and (b) task performance.

Given our conceptualization of task strategy as a more proximal behavioral outcome of personality, we propose task strategy will mediate the borderline personality-task performance relationship. Individuals with higher borderline scores are likely to have trouble developing strategies, limiting both the number and likely the quality of their strategies (Campbell, 1991). This would lead them to have lower task performance. Conversely, individuals with lower borderline scores would be likely to generate more strategies; thus they would be able to come up with potentially better strategies, which would lead them to have better task performance.

H6. Task strategy mediates the relationship between borderline personality and task performance.

All of the previously mentioned studies examining the relationship between borderline personality and performance were conducted on patients from clinical populations and comparisons were made to nonclinical participants. In this study, we examine a nonclinical sample of undergraduate students permitting our results to generalize to a larger population of educated individuals who display some BPD features and are likely to seek employment. We also examine performance on a manufacturing task in order to more closely assess the influence of each BPD feature on task strategy and task performance. To date, little research has been conducted on the influence of BPD on complex tasks that warrant more strategizing and more closely approximate the tasks performed in employment settings.

\section{Method}

\subsection{Participants}

One hundred eighty students from the psychology subject pool participated in this study. The average age of the participants was $19.0(\mathrm{SD}=3.85)$. Of the 180 participants, $42 \%$ were male, $56 \%$ were female, and $2 \%$ unknown. The majority of the sample was Cauca$\operatorname{sian}(75 \%)$.

\subsection{Procedure}

Participants were instructed to complete "The Manufacturing Game," a low fidelity manufacturing simulation in which individual participants build models of a car, a robot, or a boat using Lego $\odot$ blocks (Zaccaro, Foti, \& Kenny, 1991). The pieces needed to build each model, as well as the prices to sell, varied by model type. This information was provided in both oral and written instructions $10 \mathrm{~min}$ before the task began. One experimenter served as the buyer of models and supplier of parts. This task could be classified as a decision-making, executing performance task (McGrath, 1984). The object of the "game" is to maximize one's profit.

\subsection{Measures}

\subsubsection{Borderline personality}

The Personality Assessment Inventory Borderline Scale (PAIBOR Morey, 1991) measures four subscales described previously, using six items per dimension. Although we did not have specific hypotheses about the Negative Relationships subscale, we included it in the study and in the correlation table for completeness.

Each item is coded on a four point response scale, with response options ranging from 0 to 3 "False (Not true at all)", "Slightly True", "Mainly True", and "Very True". Consistent with the PAI manual (Morey, 2007), each subscale was calculated by reverse scoring appropriate items, summing the items, and converting them to $t$ scores. Similarly, the borderline personality full scale score was calculated by summing the raw scores on each of the subscales and converting to $t$-scores. A score of 70 is above the expected population rate and indicates likely candidacy for a diagnosis of Borderline Personality Disorder (American Psychiatric Association, 1994). Six (3\%) participants scored 70 or higher.

\subsubsection{Task strategies}

Based on a pilot study, multiple effective task strategies for the experimental task were identified. Hypothesis-blind experimenters were instructed to count the number of times each participant displayed one of the following seven behavioral strategies that were identified as effective: buying pieces for multiple models (more than one type of model and/or more than one model), building the most profitable model, putting the wheels on the car last, building more than one model at a time, mapping building colors to similar colors in the model (e.g., red with orange), in process quality check (comparison of new model to existing model or two-dimensional diagram while building), and final quality check (comparison of new model to existing model or two dimensional diagram upon completion of each model). 


\subsubsection{Task performance}

Following a 10-min practice session, performance was determined by the amount of profit the participant earned at the end

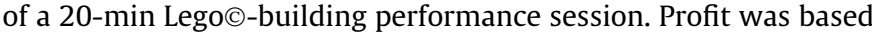
on the amount of money earned from selling their Lego $\odot$ models minus the amount of money given at the start of the session. If a model was built incorrectly, no money was earned and the pieces for the rejected model were forfeited.

\subsubsection{Control variables}

Given the significant relationship between cognitive ability and performance (Hunter \& Hunter, 1984) as well as the tendency for men to perform better on the experimental task than women, we controlled for sex and cognitive ability in all analyses. Cognitive ability was assessed with the Wonderlic Personnel Test, a 50-item, 12-min timed exam scored as the total number of items correct (Wonderlic, 2000).

\section{Results}

\subsection{Hypothesis 1}

Descriptive statistics, correlations, and reliabilities are presented in Table 1 . Hypothesis 1 proposed that task strategy is positively related to task performance. Consistent with expectations, task strategy was positively related to task performance $(r=.32$, $p<.01$ ); thus, $10 \%$ of the variance is shared between task strategy and task performance.

\subsection{Hypotheses $2-4$}

Hypotheses 2-4 proposed that multiple facets of Borderline Personality (self-harm, affective instability, and identity problems) would be related to both task strategy and task performance. After controlling for sex and cognitive ability, self-harm was not significantly related to task strategy $(r=-.12, p>.05)$ or task performance $(r=-.05, p>.05)$. Additionally, affective instability was not related to task strategy $(r=-.12, p>.05)$ or task performance $(r=.04, p>.05)$. Finally, identity problems was also not related to task strategy $(r=-.12, p>.05)$ or task performance $(r=-.03$, $p>.05)$. Therefore, Hypotheses 2-4 were not supported.

\subsection{Hypothesis 5}

Hypothesis $5 \mathrm{a}$ and $5 \mathrm{~b}$ proposed that borderline personality is negatively related to task strategy and task performance, respectively. As predicted, Borderline $T$ Score was negatively related to task strategy $(r=-.17, p<.05)$, but it was not significantly related to task performance $(r=.01, p>.05)$.

\subsection{Hypothesis 6}

Hypothesis 6 proposed that task strategy mediates the borderline personality-task performance relationship. MacKinnon and his colleagues advocate that a significant relationship between the independent and dependent variables is not a necessity for mediation (MacKinnon, Lockwood, Hoffman, West, \& Sheets, 2002). Taylor, MacKinnon, and Tein (2008) explain that "if the mediated and direct effects have opposite signs, the total effect may be near zero, even though the mediated effect is significantly nonzero" (p. 244). Correspondingly we proceeded to test for mediation even though borderline personality was not significantly related to task performance. Consistent with Baron and Kenny's (1986) third step in the test for mediation, we regressed task performance on borderline personality $(\beta=.06, p>.05)$ and task strategy $(\beta=.31, p<.05)$ simultaneously. Sobel's (1982) $t$-test confirmed that the indirect effect of borderline personality on task performance through task strategy $(t=-2.01$, $p<.05$ ) was significantly different from zero, providing some support for Hypothesis 6 .

\section{Discussion}

Previous research has shown that individuals with Borderline Personality Disorder are less likely to perform as well at work than individuals with other Axis II disorders (Zanarini et al., 2005). We argue that it is important for organizations to understand why features of borderline personality adversely affect job performance because each subscale reflects elements of personality that are present in varying amounts within all individuals (Oldham, 1995). Specifically, the combination of these features presents unique challenges to individuals with high levels of these characteristics. Therefore managers of organizations should be aware of the extent to which high levels of borderline features can affect organizational outcomes such as performance.

Whereas some research has examined the influence of BPD on task performance (Bazanis et al., 2002; Rentrop et al., 2008; Zanarini et al., 2005), no studies have included a work-related task. Further, researchers have not attempted to empirically test and validate theories about why borderline personality has adverse effects on performance. We contribute to this research literature by examining the influence of borderline personality on the number of effective task strategies demonstrated as well as overall task performance.

Our findings revealed that, borderline personality features were not significantly related to the demonstration of good task strategies. However, the construct of borderline personality is best understood when conceptualized as the interrelationships among each of its facets. In line with this, borderline personality was shown to negatively relate to the generation of task strategies. Thus the cumulative effect of high levels of multiple features ap-

Table 1

Descriptive statistics and correlations among the study variables.

\begin{tabular}{|c|c|c|c|c|c|c|c|c|c|c|c|}
\hline & $M$ & SD & 1 & 2 & 3 & 4 & 5 & 6 & 7 & 8 & 9 \\
\hline 1. Sex $(1=$ men, 2 = women $)$ & 1.57 & 0.50 & - & & & & & & & & \\
\hline 2. Cognitive ability & 27.80 & 5.46 & $-.16^{*}$ & - & & & & & & & \\
\hline 3. Borderline $T$ Score & 51.88 & 8.09 & $.16^{*}$ & .01 & $(.81)$ & $.58^{* *}$ & $.72^{* *}$ & $.76^{* *}$ & $.75^{* *}$ & $-.17^{*}$ & .01 \\
\hline 4. Self-harm & 51.67 & 10.27 & .10 & .02 & $.62^{* * *}$ & $(.70)$ & $.17^{*}$ & $.30^{* *}$ & $.18^{*}$ & -.12 & -.05 \\
\hline 5. Affective Instability & 49.52 & 8.40 & .01 & .05 & $.74^{* * *}$ & $.23^{* *}$ & $(.70)$ & $.37^{* *}$ & $.47^{* *}$ & -.12 & .04 \\
\hline 6. Identity Problems & 53.28 & 8.61 & $.15^{*}$ & .02 & $.78^{* *}$ & $.37^{* *}$ & $.42^{* *}$ & $(.57)$ & $.44^{* *}$ & -.12 & -.02 \\
\hline 7. Negative Relationships & 51.30 & 8.79 & $.21^{* *}$ & -.05 & $.76^{* *}$ & $.24^{* *}$ & $.50^{* *}$ & $.47^{* *}$ & $(.59)$ & -.13 & .03 \\
\hline 8. Task strategy & 24.57 & 18.99 & $-.19^{* *}$ & $.17^{*}$ & $-.20^{* *}$ & $-.15^{*}$ & -.12 & $-.15^{*}$ & $-.17^{*}$ & $(.71)$ & $.32^{* * *}$ \\
\hline 9. Task performance & 11011.29 & 8737.90 & $-.15^{*}$ & $.27^{* *}$ & -.02 & -.07 & .04 & -.05 & -.01 & $.36^{* *}$ & - \\
\hline
\end{tabular}

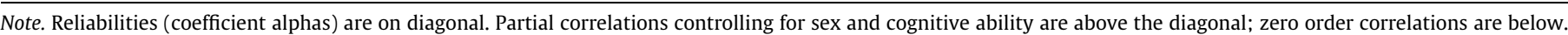
${ }^{*} p \leqslant .05$.

$p \leqslant .01$ (two-tailed). 
pears to result in the most adverse outcome (least number of effective task strategies).

Consistent with our theorizing and previous empirical research (e.g., Audia et al., 1996) that task strategy is a proximal behavioral outcome that influences task performance, task strategy had a significant positive relationship with task performance. Thus, the more strategies generated, the better the participants performed on the task. As a result, it may be an important intermediate outcome variable in which to target training and interventions.

Contrary to expectation, neither borderline personality, nor any of its features were significantly related to task performance. Thus, it appears that borderline personality does not have a direct effect on task performance; rather it potentially has an indirect effect on performance through task strategies. This again suggests the need to target interventions at how to plan and generate task strategies which in turn results in better job performance.

\subsection{Limitations and future directions}

This study revealed how a nonclinical college student sample scores on the PAI-BOR and subsequently performed on a work-related task. Researchers who wish to examine this topic further may consider prescreening participants from a nonclinical population in an effort to include more individuals that score high on the BOR scale or examine a non-college student sample to test the generalizability of our findings.

We conducted our study in a laboratory setting, which permits a large amount of experimental control. However, additional research is needed with nonclinical employed samples and more traditional measures of job performance (e.g., supervisory ratings) in order to understand how borderline personality affects actual job performance in working populations.

The experimental task was designed in this study to be completed by one participant at a time and within a short time frame. The extent to which our findings would generalize to group tasks in less time-constrained contexts remains to be determined. In order to more fully explore the effect of borderline personality on job performance, additional studies utilizing different tasks will need to be conducted.

\section{Conclusions}

Roughly 4.3 million adults in the United States could potentially have BPD and millions more exhibit some of its features. We have identified multiple behaviors linked to BPD that we theorize to be problematic in employment settings and our study contributes to the empirical evidence supporting these patterns.

\section{References}

American Psychiatric Association (1994). Diagnostic and statistical manual of mental disorders (4th ed.). Washington, DC: American Psychiatric Association.

Audia, G., Kristof-Brown, A., Brown, K. G., \& Locke, E. A. (1996). Relationship of goals and microlevel work processes to performance on a multipath manual task Journal of Applied Psychology, 81, 483-497. doi:10.1037/0021-9010.81.5.483.

Bandura, A. (1986). Social foundations of thought and action: A social cognitive theory. Englewood Cliffs, NJ: Prentice-Hall, Inc.

Baron, R. M., \& Kenny, D. A. (1986). The moderator-mediator variable distinction in social psychological research: Conceptual, strategic, and statistical considerations. Journal of Personality and Social Psychology, 51, 1173-1182. doi:10.1037/0022-3514.51.6.1173.

Bazanis, E., Rogers, D., Dowson, J. H., Taylor, P., Meux, C., Staley, C., et al. (2002). Neurocognitive deficits in decision-making and planning of patients with DSMIII-R borderline personality disorder. Psychological Medicine, 32, 1395-1405. doi:10.1017/S0033291702006657.

Campbell, D. J. (1988). Task complexity: A review and analysis. Academy of Management Review, 13, 40-52. doi:10.2307/258353.

Campbell, D. J. (1991). Goal levels, complex tasks, and strategy development: A review and analysis. Human Performance, 4(1), 1-31. doi:10.1207/ s15327043hup0401_1.
Campbell, J. P. (1990). Modeling the performance problem in industrial and organizational psychology. In M. D. Dunnette \& L. M. Hough (Eds.), Handbook of industrial and organizational psychology (pp. 687-732). Palo Alto, CA: Consulting Psychologist Press.

Campbell, J. P. (1999). The definition and measurement of performance in the new age. In D. R. Ilgen \& E. D. Pulakos (Eds.), The changing nature of performance. Implications for staffing, motivation, and development (pp. 399-429). San Francisco, CA: Jossey-Bass.

Campbell, J. P., McCloy, R. A., Oppler, S. H., \& Sager, C. E. (1993). A theory of performance. In N. Schmitt \& W. C. Borman (Eds.), Personnel selection in organizations (pp. 35-70). San Francisco, CA: Jossey-Bass.

Forgas, J. P., \& George, J. M. (2001). Affective influences on judgments and behavior in organizations: An information processing perspective. Organizational Behavior and Human Decision Processes, 86, 3-34. doi:10.1006/obhd.2001.2971.

Grinker, R. R., Werble, B., \& Drye, R. C. (1968). The borderline syndrome. New York: Basic Books.

Gunderson, J., Kolb, J., \& Austin, V. (1981). The diagnostic interview for borderline patients. American Journal of Psychiatry, 138, 896-903.

Hochhausen, N. M., Lorenz, A. R., \& Newman, J. P. (2002). Specifying the impulsivity of female inmates with borderline personality disorder. Journal of Abnormal Psychology, 111(3), 495-501. doi:10.1037/0021-843X.111.3.495.

Hunter, J. E., \& Hunter, R. F. (1984). Validity and utility of alternative predictors of job performance. Psychological Bulletin, 96, 72-98.

Jex, S. M., \& Crossley, C. D. (2004). Organizational consequences. In J. Barling, E. K. Kelloway, \& M. R. Frone (Eds.), Handbook of work and stress (pp. 575-600). Thousand Oaks, CA: Sage.

Leader, M. W. (1994). Borderline Personality Disorder and Career Issues. Ph. D Dissertation, College of Education, Georgia State University, Atlanta, GA.

Locke, E. A., Shaw, K. N., Saari, L. M., \& Latham, G. P. (1981). Goal setting and task performance: 1969-1980. Psychological Bulletin, 90(1), 125-152. doi:10.1037| 0033-2909.90.1.125.

MacKinnon, D. P., Lockwood, C. M., Hoffman, J. M., West, S. G., \& Sheets, V. (2002). A comparison of methods to test mediation and other intervening variable effects. Psychological Methods, 7, 83-104. doi:10.1037/1082-989X.7.1.83.

McGrath, J. E. (1984). Groups: Interaction and performance. Englewood Cliffs, NJ: Prentice-Hall, Inc.

Morey, L. C. (1991). The Personality Assessment Inventory professional manual. Odessa, FL: Psychological Assessment Resources.

Morey, L. C. (1996). An interpretive guide to the Personality Assessment Inventory (PAI). Odessa, FL: Psychological Assessment Resources.

Morey, L. C. (2007). Personality Assessment Inventory professional manual (2nd ed.). Odessa, FL: Psychological Assessment Resources.

Motowidlo, S. J. (2003). Job performance. In W. C. Borman, D. R. Ilgen, R. J. Klimoski, \& I. B. Weiner (Eds.). Handbook of psychology: Industrial and organizational psychology (Vol. 12, pp. 39-53). Hoboken, NJ: John Wiley \& Sons.

Oldham, J. M. (1995). The new personality self-portrait: Why you think, work, love, and act the way you do. New York, NY: Bantom.

Rentrop, M., Backenstrass, M., Jaentsch, B., Kaiser, S., Roth, A., Unger, J., et al. (2008). Response inhibition in the borderline personality disorder: Performance in a go/ nogo task. Psychopathology, 41, 50-57. doi:10.1159/000110626.

Salz, C. (1983). A theoretical approach to the treatment of work difficulties in borderline personalities. Occupational Therapy in Mental Health, 3(3), 33-46. doi:10.1300/J004v03n03_03.

Sanislow, C. A., Grilo, C. M., Morey, L. C., Bender, D. S., Skodol, A. E., Gunderson, J. G., et al. (2002). Confirmatory factor analysis of DSM-IV criteria for borderline personality disorders: Findings from the Collaborative Longitudinal Personality Disorders Study. American Journal of Psychiatry, 159, 284-290. doi:10.1176/ appi.ajp. 159.2.284

Sobel, M. E. (1982). Asymptotic intervals for indirect effects in structural equations models. In S. Leinhart (Ed.), Sociological methodology (pp. 290-312). San Francisco: Jossey-Bass.

Taylor, A. B., MacKinnon, D. P., \& Tein, J. Y. (2008). Tests of the three-path mediated effect. Organizational Research Methods, 11, 241-269.

Terborg, J., \& Miller, H. (1978). Motivation, behavior, and performance: A closer examination of goal-setting and monetary incentives. Journal of Applied Psychology, 63, 29-39. doi:10.1037/0021-9010.63.1.29.

Trull, T. J., Useda, D., Conforti, K., \& Doan, B. (1997). Borderline personality features in nonclinical young adults: 2. Two-year outcome. Journal of Abnormal Psychology, 106(2), 307-314. doi:10.1037/0021-843X.106.2.307.

US Census Bureau (2008). T1. Population Estimates [11]. from <http:// factfinder.census.gov/servlet/DTTable?_bm=y\&-geo_id=01000US\&-ds_name=PEP_ 2008_EST\&-redoLog=false\&-mt_name=PEP_2008_EST_G2008_T001> Retrieved 27.05.09.

Wonderlic (2000). The wonderlic personnel test. Libertyville, IL: Wonderlic, Inc.

Zaccaro, S. J., Foti, R. J., \& Kenny, D. A. (1991). Self-monitoring and trait-based variance in leadership: An investigation of leader flexibility across multiple group situations. Journal of Applied Psychology, 76, 308-315. doi:10.1037/00219010.76.2.308.

Zanarini, M. C., Frankenburg, F. R., Hennen, J., Reich, D. B., \& Silk, K. R. (2005) Psychosocial functioning of Borderline patients and Axis II comparison subjects followed prospectively for six years. Journal of Personality Disorders., 19(1) 19-29. doi:10.1521/pedi.19.1.19.62178. 